Supporting first-grade writers who fail to learn: Multiple single case evaluation of a Response-to-Intervention approach

María Arrimada $^{1}$, Mark Torrance $^{2}$ and Raquel Fidalgo ${ }^{1}$

1 Department of Psychology, Sociology and Philosophy. Faculty of Education.

University of León, campus de Vegazana s/n, PC. 24071, León (Spain).

2 Department of Psychology. School of Social Sciences. Nottingham Trent University, Burton Street, Nottingham (United Kingdom), NG1 4BU.

Corresponding author: María Arrimada

marrg@unileon.es

+34 651399144

Authors' acknowledgments: Study funded by a 2016 BBVA Foundation Grant for Researchers and Cultural Creators awarded to the third author. This work has also been benefitted from support from the COST Action IS1401 ELN. A Spanish predoctoral grant (FPU) by the Ministry of Education, Culture and Sports was awarded to the first author during this study. 


\section{Supporting first-grade writers who fail to learn: Multiple single-case evaluation of a Response to Intervention approach}

We report a multiple-baseline single-case study, based in the Response to Intervention framework, evaluating Transcription-Only and Transcription-and-Planning interventions for young, struggling writers. In a baseline phase, 8 classes of Spanish children at the start of their first year of primary (elementary) education completed short, probe writing tasks twice- weekly over the first 120 days of their school career. During this period, all students received researcherdeveloped classroom instruction in spelling, handwriting, and text-planning. Students then completed a battery of tests including measures of spelling, handwriting and composition quality. On the basis of writing probe tasks and test scores we identified 12 struggling writers for whose written composition performance was below the 15th percentile, relative to the full sample, whose spelling performance was below 25th percentile, and whose handwriting was poor. For the next 72 days, these students received twice-weekly, parent-delivered training in transcription skills (handwriting and spelling) or transcription skills plus text planning. Researcher-developed classroom instruction and regular probe tasks continued during this phase. All students, in both intervention conditions, showed improvement in handwriting quality relative to Phase 1.10 students also showed improvement in composition quality, with 8 performing, post intervention, within normal range relative to peers. Our findings demonstrate the value of a Response-toIntervention approach to identification and remediation for struggling writes in their first school year.

Keywords: handwriting, spelling, planning instruction, writing learning difficulties, strategyfocused writing instruction 


\section{Introduction}

Learning to compose text requires a range of skills. According to the not-so-simple view of writing (Berninger \& Winn, 2006), these involve low-level transcription skills and high-level self-regulation skills. Transcription is the ability to transform linguistic representations into written text by retrieving the orthographic symbols and executing the motor output required to produce them (Abbott \& Berninger, 1993). Thus, it involves handwriting and spelling. Skilled writing also requires high-level skills to direct the composing process and meet multiple environmental demands. Among them, planning strategies for generating and structuring ideas seem particularly important in early educational stages, where children are required not only to generate but also to organize ideas to create specific text genre.

Low and high-level skills are closely interrelated. According to Berninger \& Winn (2006), lack of automaticity in transcription draws cognitive resources from higher level processing, keeping writers from activating both processes concurrently (see also Limpo \& Alves, 2013a; McCutchen, 1996; Olive \& Kellogg, 2002). This will affect the content and rhetoric of the child's text. Struggling with transcription is also likely to constrain learning. A child who struggles with handwriting will produce less text, providing teachers with less scope for feedback: if a child struggles to form words, it is impossible to determine whether they have developed, for example, grammar knowledge or understanding of how to construct a narrative. Over time, handwriting difficulties has the potential to spiral into a serious failure to learn to compose effective text.

Several studies have examined the efficacy of interventions for supporting development of writing skills in struggling writers (Gersten \& Baker, 2001; Gillespie \& Graham, 2014), though very few were conducted at the beginning of compulsory education. Given that it is possible to detect early signs of future writing failure, research supports the use of early supplementary writing interventions to prevent or alleviate problems in later grades (Graham, Harris, \& Larsen, 2001). Thus, we propose a relatively low-effort intervention for early failure to learn to write.

In our contribution to this special issue we describe a Response to Intervention (RTI) approach (Barnes \& Harlacher, 2008; Vaughn \& Fuchs, 2003) that aims to identify and then remediate failure to learn 
to write at the start of school career. RTI is "a systematic and data-based method for identifying, defining and resolving students' academic and/or behavioural difficulties" (Brown-Chidsey \& Steege, 2005, p.2). All learners are initially exposed to evidence-based classroom instruction (Tier 1) and their learning is systematically monitored. When progress-monitoring data reveals slow learning, these students are given additional (Tier 2) support. Students who still struggle would receive further support (Tier 3). Several studies have established the value of RTI in reading (O’Connor, Fulmer, Harty, \& Bell, 2005; Simmons et al., 2008; Vaughn, Linan-thompson, \& Hickman, 2003) and a combination of reading and mathematics (Vanderheyden, Witt, \& Gilbertson, 2007). They conclude that this approach - which combines classroom evidence-based intervention, systematic evaluation of learning in a controlled context and additional support for failing students - is particularly successful to enabling initially at-risk students to catch up with their peers.

To our knowledge, although some studies have referred to remedial instruction as Tier 2 (Harris, Graham, \& Adkins, 2015; Lane et al., 2011), RTI has never been formally implemented as a strategy for identifying and supporting struggling writers. In the context of writing instruction, RTI seems particularly suitable since it allows assessing failure over time and ensures the use of standardized, evidence-based instruction before diagnosing failure to learn. Progress monitoring is needed since the literacy skills of children entering first grade are highly variable (Coker, 2006; Dunsmuir \& Blatchford, 2004; Hooper, Roberts, Nelson, Zeisel, \& Kasambira, 2010) and scores on single writing tasks typically provide poor indication of writers' ability, particularly in younger students (Van den Bergh, Maeyer, van Weijen, \& Tillema, 2012). Concerning instruction, Tier 1 intervention is based in current evidence, which helps to eliminate the possibility of students failing to learn due to poor instruction. There is, fortunately, a rich literature exploring the efficacy of different forms of writing instruction to inform choice of an evidencebased Tier 1 intervention (Graham \& Harris, 2015; Graham, Mckeown, Kiuhara, \& Harris, 2012).

A central question for writing instruction in first grade, is the relative benefit of teaching low-level (transcription) and high-level (composition) skills. In a meta-analysis, Graham \& Santangelo (2014) found 
only one unpublished study that showed statistically significant effects of spelling instruction on compositional quality in first and second grade. Handwriting, however, has proved particularly valuable in children's writing development. Individual differences in handwriting significantly predict compositional fluency and quality (Jones \& Christensen, 1999; Berninger et al., 1997) and poor handwriting hampers composition, preventing writers to engage in more complex writing processes (McCutchen, 1996). In a separate meta-analysis, Santangelo and Graham (2016) identified three studies in which handwriting instruction showed benefits for text length and fluency - as might be expected - but also for text quality, effect sizes between .54 and 1.00 (Alves et al., 2016; Graham, Harris, \& Fink, 2000; Jones, 2004). There is some evidence, therefore, that, for handwriting at least, teaching low-level skills has knock-on benefits for higher-level text features. In our study, handwriting performance was the main selection criteria as a possible reason to explain early failure to develop composition skills.

There is also evidence that direct instruction in text planning, benefits young, struggling writers (Single-case studies: Lane et al., 2008; Zumbrunn \& Bruning, 2013. Group comparisons: Harris, Graham, \& Mason, 2006; Harris et al., 2015; Lane et al., 2011; Lienemann, Graham, Leader-Janssen, \& Reid, 2006). Except for Zumbrunn and Bruning, a case study of 6 first graders, these studies were conducted with second-grade students. Taken together, they provide evidence that teaching young struggling students how to plan their text benefits text structure, length and overall quality. To our knowledge, however, our recent research (authors, submitted) is the only study that found robust effects of teaching planning strategies to fully-range first-grade classes on the quality of students' narratives.

Although transcription and planning have traditionally being taught separately, writing requires the concurrent activation of both. It, therefore, makes sense to conduct interventions addressing the early development of all core cognitive processes involved in writing. This will provide better insight into the interrelation of low and high-level skills in young writers and subsequent clues to support struggling students. Current evidence suggests that combined instruction in transcription and planning produces greater benefits on writing fluency and quality than pure planning instruction (Limpo \& Alves, 2017). 
In most of these studies, instruction was delivered by researchers to small groups of students. While this maximizes fidelity and effect size, it reduces generalizability to typical classroom settings. Thus, in the present study, classroom instruction (Tier 1) was conducted by teachers, increasing its applicability to real school contexts. However, in full-range classrooms, teachers will not typically have time to provide intensive additional support for students who fail to learn. We therefore implemented a Tier 2 intervention based on tasks that students completed under their parents' supervision. Evidence supports the value of parent involvement in developing students' writing skills, albeit students above first grade. This is true for spelling (Camacho \& Alves, 2017; Karahmadi, Shakibayee, Amirian, Bagherian-Sararoudi, \& Maracy, 2013; Reutzel, Fawson, \& Smith, 2005) but also for productivity and compositional quality (Robledo-Ramón \& GarcíaSánchez, 2012; Saint-Laurent \& Giasson, 2005).

\section{The present study}

This study involved a rigorous, year-long implementation of an RTI approach to writing instruction for first-grade students. Our aim was to explore the effectiveness of this approach to providing remedial support for students who struggle to learn to write in their first year of formal education. Slow learners in the present study were defined as those whose poor composition skills are accompanied (and possibly caused by) very poor handwriting.

The RTI approach adopted in this paper differs from previous interventions for teaching composition skills to young struggling writers (Harris et al., 2006; Harris et al., 2015; Lane et al., 2008; Lane et al., 2011; Lienemann et al., 2006; Zumbrunn \& Bruning, 2013) in three important ways. First, we studied writers at the very beginning of their school career. With one exception (Zumbrunn \& Bruning, 2013) all previous studies involve writers in second grade. Second, previous studies have identified students who fail under the normal curriculum, in the context of teacher-developed instruction. We, however, consistent with the RTI framework, identified failure to learn in the context of a systematic evidence-based writing instruction. This involved combined instruction in transcription and planning for all students in 8 first-grade classes (Phase 1). Evaluation under this Tier 1 intervention reduced the possibility that students failing to 
learn struggled simply because of deficiencies in the instruction. Struggling students were provided with Tier 2 additional remedial instruction (Phase 2). This involved regular tasks, overseen by parents, which provided additional practice in the skills taught in the Tier 1 instruction. The Tier 2 intervention took two forms: Transcription-Only and Transcription-and-Planning. A No Intervention group, which received no additional support, was compared with intervention students. Students' progress was monitored in both tiers. Within this context, we explored the benefits of additional support (Tier 2) for 12 struggling students. Third, students in need of remediation are typically identified through assessments at a single point in time. However, consistent with the progress monitoring approach of RTI, we identified failure to learn in terms of rate of learning.

Our study addressed this research question: Is the implementation of a rigorous RTI approach to first-grade instruction effective in remediating early failure to learn written composition skills in a sample of children who specifically struggled with handwriting? We identified slow learners on the basis of scores from multiple probe tasks completed at regular intervals throughout the first half of the academic year. From these, we selected just those students who also showed poor or very poor handwriting. These children received additional, parent-supervised (Tier 2) support. We compared students' learning trajectories prior to Tier 2 intervention with their learning during Tier 2 intervention. We also compared performance on one-off, pre-post measures of spelling, narrative writing, handwriting fluency and non-verbal ability. If Tier 2 intervention was effective, we anticipated that intervention students would show improved performance and accelerated learning during Tier 2 intervention, and perform within normal range on writing post-tests. Failure to find parallel improvement in non-verbal performance, and in a comparison case studies of students who did not receive Tier 2 supper, would rule out maturational (“late developing”) explanations for this finding.

\section{Method}

\section{Design}

Our case study was conducted in two stages over one academic year: a baseline phase (Phase 1) 
in which we assessed the performance of a relatively large cohort under Tier 1 classroom instruction, and an intervention phase (Phase 2) during which students who struggled in Phase 1 were given additional Tier 2 support while they continued receiving Tier 1 classroom instruction

During Phase 1, for the first 120 days of the year, 179 first-grade students completed short text writing probe tasks twice-weekly (with some variation in regularity across classes). They also received empirically-based writing instruction 3 times a week, focused on transcription and planning (Tier 1). At pretest and Phase 1 posttest (before and after Phase 1), we measured, for the full cohort, performance on several phase-end tests: spelling, handwriting speed, narrative writing and non-verbal ability, to act as a non-verbal control. After Phase 1, we estimated performance on overall text quality on the probe tasks through linear regression models fitted separately for each child. All students whose estimated performance was below the $25^{\text {th }}$ percentile received additional Tier 2 support in Phase 2 . We then examined their scores on the phase-end tests. For the purpose of this paper, we identified a sub-group of 13 students who met two inclusion criteria: a) estimated performance on the regular probe tasks below the $15^{\text {th }}$ percentile and $\mathrm{b}$ ) handwriting in the phase-end narrative writing task rated as poor or very poor. Scores on spelling and handwriting speed at the phase-end tests were at or below the $25^{\text {th }}$ percentile in 11 and 8 students respectively. In this paper, we report results for just this subset of 13 students who met the two inclusion criteria. However, all students who performed below the $25^{\text {th }}$ percentile in the probe tasks received some form of Tier 2 intervention.

Phase 2 started 40 days after Phase 1, and lasted for 72 days. Children who showed slow development in Phase 1 received additional Tier 2 support. This involved twice-weekly homework tasks, overseen by parents. The intervention children were split randomly between two conditions: The Transcription-Only intervention comprised tasks focused on handwriting and spelling accuracy and automaticity; the Transcription-and-Planning intervention involved a subset of these transcription tasks, plus additional planning tasks. Additionally, we identified a No Intervention comparison group selected randomly from students whose estimated performance in the probe tasks during Phase 1 was between 
the $25^{\text {th }}$ and $50^{\text {th }}$ percentile, just above the level that triggered intervention.

As in Phase 1, all students continued receiving Tier 1 instruction and completed bi-weekly probe writing tasks. According to RTI, Tier 1 instruction aims not only to identify struggling students, but also to continuously provide all children with evidence-based instruction (Barnes \& Harlacher, 2008). At the end of Phase 2, students again repeated the phase-end tests.

\section{Participants}

An initial sample of 179 students $(85$ male, mean age $=6.1)$ from 8 first-grade classes took part in the study. They were distributed in 3 schools located in a middle-class area. All of them received Tier 1 instruction throughout the whole academic year.

A sub-group of 13 participants were selected for this study and received Tier 2 instruction. One student was removed because they did not complete the intervention. The remaining 12 were split in two conditions: Transcription-Only $(\mathrm{N}=5,1$ female, mean age $=6.2$ years $)$ and Transcription-and-Planning $(\mathrm{N}=7,3$ female, mean age $=6$ years $)$. None of these students had previous medical diagnosis of disabilities. Seven of the eight classes had at least one student and no more than three receiving Tier 2 instruction. A third No Intervention comparison group was added $(\mathrm{N}=7$, female $=3$, mean age $=6.06)$.

\section{Educational Context}

Compulsory education in Spain starts with children entering first grade in September of the year in which they reach 6 years old. However, all students in our sample had attended kindergarten where writing instruction addresses handwriting and spelling. Handwriting instruction involves naming and shaping the letters, progression from left to right, following lines on the page and allographs' size. Spelling involves regular phoneme-grapheme correspondence and the writing of simple syllables and words. Transcription is taught to the whole class, without individualized teaching or instruction taken at each child's pace. Transcription is not formally assessed. Curricula highlights the need for parents to participate in the learning process though no specific procedures are set.

\section{Measures}


We monitor students' progress and determined their rate of learning via regular text writing probe tasks, rated weekly for overall length, spelling, handwriting accuracy and overall quality. Additionally, we assessed non-verbal ability, spelling, handwriting speed and narrative writing at pretest (before Phase 1), Phase 1 posttest (after Phase 1) and Phase 2 posttest (after Phase 2).

\section{Progress monitoring measures.}

Students completed short text writing probe tasks asking for narrative descriptions of events in their own lives (e.g., "What did I do yesterday?”, "How did I celebrate my last birthday?”). Across the year, students completed a minimum of 20 probes (mean $=33$ ). Students wrote for 10 minutes. Word count was recorded as a measure of productivity, independent of spelling or handwriting. Letter strings were considered words if they were separated from other strings and/or phonologically interpretable as attempted words. Spelling accuracy was the number of correctly spelled words. Handwriting quality was measured on a 5 point-scale, ranging from "no real letters/words to assess handwriting" to "very neat handwriting". Global quality was rated on a 6 point-scale, ranging from "very poor quality" to "very high quality" (see Appendix A for scales). Handwriting and quality were scored by two independent raters. Inter-rater agreement, calculated using Pearson's correlation, gave a mean of .95 for handwriting and .91 for quality over the whole year.

\section{Phase-end measures.}

Non-verbal ability was assessed using a matrix task designed by the researchers to be completed quicker than, for example, Raven's Progressive Matrices (Raven, 1981). The task contained three sets of incomplete matrices: patterns, sequences of identical figures and geometrical figures. Students circled, among 6 options, the picture that completed each matrix. This test showed reasonable internal and test-retest reliability (Chronbach's alpha, start-of-year $=.73$, mid-year $=.67$, end-year $=.66$. Test-retest: start-of-year vs. midyear, $r=.65$; mid-year vs. end-year, $r=.68$ ). Correlation with spelling ability, as an indicator of discriminant validity, was .40 at start of year, .36 mid-year and .29 at end of year. 
Spelling ability was assessed through real and pseudo-word spelling-to-dictation tasks. Real words comprised 12 bisyllabic and trisyllabic medium-frequency words selected from the Spanish dictionary of word frequency in children's writing (Martínez \& García, 2004) according to the criteria outlined by Defior, Jiménez-Fernández and Serrano (2009). Pseudo-words comprised 12 non-words with the same syllabic structure as the words. Each word/pseudo-word was scored from 0 to 2 points: 2 was given to correctly spelled words; 1 was given if no more than 2 spelling errors were made; words with more than 2 errors scored 0 . For pseudo-words, spelling errors were defined as a deviation from all phonologically plausible spellings.

To assess handwriting speed, students memorised a single sentence and wrote it as many times as they could within 1 minute. The sentence - "Me gusta mucho salir al patio" ("I really like going to the playground") - was deliberately selected since it was meaningful, easy to remember and contained no irregular phoneme-grapheme correspondences. Score was the number of words written. Spelling mistakes were ignored as long as the word was phonologically similar to the original one. This way we measured handwriting speed as purely as possible, without spelling interfering.

To assess narrative writing, students were asked to write a story, choosing their own topic, or relating one they already knew. They were instructed to think carefully about what they were writing and to write as clearly as possible. Forty minutes were given to complete the task. Text quality was assessed through an adapted version of the method used by Cuetos, Sánchez and Ramos (1996). This involved identifying the presence or absence within the text of 10 different narrative features: temporal references, spatial references, main characters, character description, opening event, emotional reactions, any mention of action, progression of ideas, final consequence and sophisticated vocabulary. Maximum score for a text was 10. Two raters scored the texts. Inter-rater agreement gave a mean of .95 at pretest, .92 at Phase 1 posttest and .91 at Phase 2 posttest across all measures.

\section{Tier 1 classroom instruction}

All 179 students received Tier 1 intervention in three sessions per week (15-20 minutes) throughout 
Phases 1 (54 sessions) and 2 (29 sessions). It focused on handwriting, spelling, sentence-combining and planning. These components alternated, so three of them were taught each week (one component per session).

Handwriting and spelling instruction drew heavily on previous work on transcription skills (Graham, Harris, \& Fink, 2002; Graham et al., 2000). Adaptations were made to accommodate the shallow nature of Spanish orthography, and the age of the students (extensive use of games, songs and pictures).

Handwriting instruction comprised 24 sessions, each set of 6 sessions addressing 7 letters of the alphabet. The instructional sequence for each set was as follows. First, students memorised the alphabetic sequence (2 sessions). Second, students traced letters and then form them without support (2 sessions). Third, handwriting speed was addressed through time-limited activities based on writing as many letters or words as possible (1 session). Finally, students wrote these letters in context by copying a text from dictation (1 session).

Spelling instruction comprised 12 sessions. Three spelling rules were explained (4 sessions per rule). The instructional sequence comprised 2 stages. First, students inferred the spelling rule with teacher's support ( 2 sessions) by analysing six target words controlled for frequency. Second, students practiced each rule in pairs through a spelling goose game designed ad hoc (2 sessions).

Sentence-combining instruction was included since Tier 1 instruction aimed at developing general written compositions skills, which necessarily include syntax skills and the construction of complex sentences (Beers \& Nagy, 2009; Berninger, Nagy \& Beers, 2011). Previous literature have demonstrated the efficacy of sentence-combining instruction (Limpo \& Alves, 2013b). After each 4 spelling sessions, 4 sessions were devoted to sentence-combining and punctuation rules. This comprised 12 sessions. Students practised sentence-combining by using simple connectors to write complex sentences ( 2 sessions). Then, they were taught a punctuation rule to be used with complex sentences or complete texts ( 2 sessions).

Planning instruction on story writing was based on previous strategy-focused interventions (Fidalgo \& Torrance, 2015; Harris et al., 2015) including 3 instructional components: direct instruction, modelling 
and individual practice. It comprised 27 sessions. First, direct instruction (12 sessions), in which students were provided with explicit metacognitive knowledge of the planning process and the structural elements of a narrative: introduction (when and where the story happens and who the characters are), development (what happens and how the characters react) and conclusion (how the story ends). These were presented as houses on the road up to a mountain used as a mnemonic device. Students then judged high and poorquality texts. Second, modelling (5 sessions) followed by students' emulative practice (4 sessions). Teachers provided students with a mastery model of the strategy use by thinking aloud while composing a narrative in front of the class. Through thinking aloud students were explicitly taught how to self-regulate their writing behaviour: aim setting, self-motivation, steps to follow the strategy and self-assessment. After each modelling session, students emulated teacher's writing. Teachers then performed an incomplete model and students identified the missing parts of the story modelled. Third, individual practice (6 sessions), students wrote their own narrative first with and then without a detailed guide of the structure. This allowed them to practice the self-regulation procedures mentioned above.

\section{Remedial (Tier 2) instruction}

Intervention students were divided in two experimental conditions: Transcription-Only and Transcription-and-Planning. Both received parent-delivered Tier 2 instruction during Phase 2. RTI assumes that those students who struggle under Tier 1 might benefit for the same instruction if taught in a more individualized way. Thus, both Tier 2 instructional programs followed the same pattern as Tier 1, with adaptations described below.

Tier 2 intervention was delivered over 22 twice-weekly sessions, on a one-to-one tutoring basis. Sessions were paper-based designed: working sheets contained all necessary explanations provided by an avatar. Both Tier 2 instructional programs matched the transcription contents in Tier 1. Planning instruction, though, was only taught in one condition. Sentence-combining was removed since it required some level of handwriting fluency and intervention children seriously struggled with handwriting. Instructional components alternated, so that two of them were taught per week. 


\section{Transcription-Only condition.}

Handwriting was the main focus of 11 sessions, while spelling was addressed in the remaining half. Necessarily, however, all sessions indirectly addressed spelling and handwriting processes involved in writing syllables or words.

Handwriting instruction matched Tier 1, with three adaptations aligned with students' poor handwriting: sub-letter forms were practice since the students struggled with even the most basic handwriting processes; not only single letters but syllables were traced and copied; text-copying was removed since it required some level of handwriting accuracy.

Spelling instruction followed Tier 1 sequence. Target words were different but selected through the same criteria.

\section{Transcription-and-Planning condition.}

Twelve sessions were devoted to transcription skills: 5 mainly focused on handwriting and 7 on spelling. Ten sessions were devoted to planning.

Spelling and handwriting instruction followed the same pattern as the Transcription-Only condition. Given the reduced number of sessions, exercises on sub-letter forms and challenging syllables were removed.

Planning instruction followed Tier 1 instructional sequence with some adaptations. Since we designed specific transcription training, we assumed planning sessions should involve as less transcription as possible so that even students who really struggled with transcription could complete planning sessions. Therefore, when children's answers in planning sessions involved writing words, ideas or texts, parents were told to write them down. Minimum transcription skills were, however, occasionally required. Direct instruction and modelling alternated to promote a better understanding of the structural parts. Thus, modelling followed direct instruction of each part of a narrative. Direct instruction was provided by the avatar in children's workbooks. Students identified the structural elements on a written text but did not judged its quality. Modelling was presented through a video performed by the first author. After 
modelling, students created their own narrative by selecting pictures and tracing the text below them. A final complete modelling was provided to increase understanding of narrative structure. Individual practice was performed without guidance, but children assessed their performance using a checklist. Given students' difficulties, all these adaptations provided a high degree of scaffolding.

\section{Delivery and fidelity}

Classroom teachers delivered Tier 1 instruction. They attended an initial training session on the instructional procedure of each writing component. A detailed script of each session was provided, and teachers kept regular meetings with the researchers. To ensure fidelity, researchers examined all the materials and found no evidence of any teacher failing to complete the prescribed tasks. Tier 1 sessions were audio-recorded. A random sample of 56 recordings were compared to the scripts given to the teachers. Although teacher's performance slightly varied across classes, steps completion gave a mean of $87 \%$. We, therefore, found no evidence of students' failing due to poor Tier 1 instruction.

Before Phase 2, parents of the intervention students met with the school principals and researchers and were presented the Tier 2 intervention as a supporting activity to classroom instruction. They all agreed to collaborate and expressed their availability to work with their child twice a week. On teachers' request, parents were trained individually or in small groups formed according to which form of Tier 2 instruction their children were receiving. The training session lasted for 1 hour. It involved an initial overview of the study followed by a detailed explanation about general instructions on how to use the materials. Parents were then told the specific procedure to complete each writing task. Contact information of the first author was provided in case they needed support throughout the intervention. Parents were allowed to rise any objections, but no one did.

The intervention tasks were paper-based and self-contained. Parents, therefore, were not expected to provide any input beyond encouragement and making sure that their child understood. Children were given a workbook which contained all the tasks and several explanatory materials for parents.

Written products from all tasks were collected by the researchers. Analyses of these indicated that 7 
students completed the 22 sessions. Four completed between $88 \%$ and $98 \%$ and 1 student completed $82 \%$ of the tasks. This indicates fidelity of the intervention.

\section{Results}

Results of the 12 intervention students and the No Intervention comparison group $(\mathrm{N}=7)$ are reported below for progress monitoring and phase-end measures.

\section{Progress monitoring}

Figures 1 to 3 show scores from the progress monitoring probe tasks. These data were analysed by linear regression models, evaluated separately for each child, with phase, time (days from start of year standardized within phase), and the phase-by-time interaction as predictors. A positive effect of phase (higher scores in Phase 2 than Phase 1) in intervention students represents evidence that that child performed better in Phase 2, during which they experienced Tier 2 intervention, than in Phase 1. A positive effect of the interaction between phase and time (a steeper slope in Phase 2 than in Phase 1) indicates that for this student learning rate in Phase 2 was greater than in Phase 1. Parameter estimates from these models are represented by the regression lines in Figures 1 to 3. Table 1 shows statistical significance of these effects, derived by evaluating parameter estimates against a t distribution. Standardised regression coefficients, $\mathrm{t}$ and degrees of freedom are presented in Appendix B.

[Insert Figures 1, 2 and 3, and Table 1 near here]

Regarding overall text quality (Figure1), 10 intervention students performed significantly better in Phase 2. This was true for only 2 students in the No-Intervention comparison group. Patterns of performance varied, however, suggesting three groups: Four students (S8, S9, S11, S15) showed little or no learning in Phase 1 but developed in Phase 2. Other students (S14, S16, S19, S20) showed some learning in Phase 1 but they still perform at or below the $15^{\text {th }}$ percentile by the end of this phase, since they started with very low ability. These continued to learn at a similar rate in Phase 2. Finally, two students $(\mathrm{S} 13, \mathrm{~S} 17)$ jumped in performance as soon as Phase 2 started, and then continued to produce texts with 
this higherquality.

Handwriting performance (Figure 2) followed similar patterns. All intervention students produced better handwriting in Phase 2. This was even true for the two students (S10, S18) who did not show improvements in overall quality, although neither of them showed handwriting learning throughout Phase 2 and still ended the phase performing at a low level. Comparison of learning rates in both phases indicates very similar patterns to overall quality. Four of the 7 comparison students also showed handwriting improvement, although with smaller gains and no additional learning during Phase 2.

Nine intervention students wrote, on average, significantly longer texts in Phase 2, and 11 produced more correctly spelled words (Figure 3). In the comparison group, 3 students wrote longer texts while 4 showed better spelling. Intervention students who did not show an overall increase in text length (S8, S9, S15) showed, however, significantly higher rate of development in Phase 2.

In summary, performance during Tier 2 improved for most students on all four measures, and for all students on at least two measures. There were no differences between the Transcription-Only and the Transcription-and-Planning conditions.

\section{Phase-end measures}

The analysis reported so far demonstrates that intervention students' performance improved in Phase 2. However, this is only partial evidence of success of the Tier 2 intervention. Ideally, by the end of Phase 2, previously struggling writers would perform at similar levels that their cohort. Appendix $\mathrm{C}$ shows the mean performance of the whole sample $(\mathrm{N}=179)$ and the individual performance of each case study participant on the phase-end tests. Figure 4 plots the scores of intervention students on the tasks performed at pretest and Phase 1 and Phase 2 posttests, relative to scores from the remainder of the cohort.

\section{[Insert Figure 4 near here]}

Regarding scores from the phase-end narrative test (Figure 4, column 1), there was good agreement between performance on this task and on the probes: students identified as struggling based on their probe tasks also scored badly on this narrative writing test at pretest and Phase 1 posttest. This indicates 
correspondence between the two quality measures used: a general researcher-designed holistic scale (probe tasks) and a more precise assessment procedure based on the specific features of narrative writing. Eight intervention students showed gains that placed them within normal range, relative to their cohort. Tier 2 intervention successfully enabled these students to catch up. Four students showed no improvement. For S10 and S18 this was expected, given their performance on the probe tasks. Tier 2 intervention was ineffective for them and they are obvious candidates for additional (Tier 3) intervention. This may also be true for S15, although they showed improvement towards the end of Phase 2. S14, however, wrote substantially better during Phase 2. This was not reflected in their performance on the narrative task, highlighting problems associated with single assessments. We found no differences between the two intervention conditions.

As expected, intervention students performed poorer than their peers on the handwriting speed task and the spelling-to-dictation task, at pretest and Phase 1 posttest (Figure 4, columns 2 and 3). We did not find consistent improvement following Tier 2 intervention. Seven students performed around the $25^{\text {th }}$ percentile on handwriting speed at the end of Phase 2, though only 3 showed gains attributed to Tier 2 (S9, S11, S17). In spelling, we observed substantial improvement only for S13.

Finally, as expected, case study students did not improve, relative to peers, their non-verbal abilities (Figure 4, column 4). This supports the fact that improvement was an effect of Tier 2 intervention and not due to simple maturation.

\section{Discussion}

This research explored whether an RTI approach to first-grade instruction is effective in remediating early failure to learn to write. With some caveats discussed below, we argue that this approach is reliable for remediation.

Overall, our results confirm that Tier 2 intervention helped most slow learners catch up with their average peers: as shown by the progress monitoring measures, we found significant improvement in the handwriting of all 12 students and in the compositional quality of 10 students. These students produced 
longer texts with more correctly spelled words. Additionally, on the phase-end narrative task, eight students showed sufficient improvement to be placed at or substantially above the $25^{\text {th }}$ percentile relative to their cohort. It might be the case that, for maturational reasons, students started to gain from Tier 1 instruction in Phase 2. However, two reasons provide evidence against this improvement having a maturational explanation: a) the comparison group did not show consistent gains and b) non-verbal ability did not improve.

Different patterns of response were found among participants. Some failed to learn in Phase 1 and then improved in Phase 2, as expected. Others learned slowly in Phase 1 but showed a sudden jump in performance at the beginning of Tier 2. Arguably, our approach is particularly important for these students. Without regular testing and individual attention, they might have remained hidden and developed a more fundamental failure to learn. A third group showed learning in both phases, but started from a very weak performance. For these students, it is less clear whether they were in need of intervention. Considering their learning slopes, they might have caught up without remedial intervention. However, selection criteria must involve estimated performance, which was considerably low for these students.

Unlike (Limpo \& Alves, 2017) we did not find evidence that giving additional training in planning, alongside transcription, was necessary for our sample of struggling writers. Note however that all students have already received planning instruction in the first part of the year and this Tier 1 intervention continued in parallel with Tier 2. Our case study students were sampled specifically because they struggled not just with narrative composition but also with handwriting. Additionally, students selected for the Tier 2 intervention seriously struggle with transcription. Within the limits of the case-study design of our research, our findings suggest that where students already have an understanding of how to plan their text, but struggle with transcription, additional support in low-level skills is, on its own, sufficient to bring the students up to speed.

We found some evidence that Tier 2 intervention resulted in improved performance on the phaseend handwriting speed task, but Tier 2 intervention did not appear to result in improved performance, 
relative to peers, on the spelling task. This suggests, perhaps, that although their spelling ability was adequate not to hold them back when writing narratives, it had not improved sufficiently to meet the more exacting demands of a formal spelling test.

On balance, therefore, we believe that the multi-tiered intervention implemented provides significant gains in writing ability. We believe that our approach also demonstrates a particularly effective way of identifying slow learners. Multiple probe tasks provide a substantially more robust estimate of writing skills (Van den Bergh et al., 2012) than one-off assessment. Crucially they also permit assessment of progress over time. Reliable identification must also eliminate the possibility of poor instruction causing slow learning. All participants in our study received evidence-based instruction throughout the whole year (Tier 1). Previous studies have demonstrated the efficacy of Tier 1 instruction for older students (Glaser \& Brunstein, 2007; Limpo \& Alves, 2013b; Torrance, Fidalgo, \& García, 2007) and our recent research suggests that this extends to first grade (Authors, submitted). Additionally, studies have demonstrated the benefits of providing additional, strategy-focused support for writers struggling under the normal curriculum (Harris et al., 2006; Lane et al., 2011; Zumbrunn \& Bruning, 2013). However, to our knowledge, identification of struggling writers and remedial Tier 2 intervention have never been addressed under ongoing, researcher-designed and evidence based Tier 1 instruction. We believe, therefore, that our method demonstrates an effective and robust identification of slow learners. Moreover, repeating this combination of regular probe tasks and Tier 1 intervention over several consecutive cohorts would provide increasingly reliable norms on which to base this judgement.

Our RTI intervention was designed to be feasible in a typical, single-teacher class. Single teachers are unlikely to provide additional support to slow learners under the pressure of regular teaching. Parents, therefore, oversaw our Tier 2 intervention. Improvement confirms previous findings on the positive effects of parental involvement in writing (Camacho \& Alves, 2017; Robledo-Ramón \& García-Sánchez, 2012). This result, however, should be treated with caution. Tier 2 involved completing the tasks under parent's supervision. This was evaluated as a whole package in which some variation in how parents 
delivered the support was expected. Our study, therefore, does not make claims about the mechanisms explaining improvement in performance. We have just demonstrated the value of a method that teachers could apply without extra support. This was also true for Tier 1 intervention: activities did not require additional resources and provided written outputs, making it straightforward to determine fidelity. The probe tasks were, however, problematic. Teachers' attitudes towards these were considerably variable. Typical practice in the context in which we conducted this research involves a bottom-up approach to writing instruction, strongly focused on transcription (Cutler \& Graham, 2008; Dockrell, Marshall, \& Wyse, 2015). Thus, teachers were reluctant to accept the value of writing full texts from early educational stages.

In this paper we have presented data from a small sample of children. Findings are therefore only suggestive and clearly our study requires replication across a much larger number of classes, yielding a larger sample of struggling students. However, as we have discussed, the design of the assessment and intervention approach that we describe in this paper should make implementation on a larger scale straightforward. Within the limitations of the evidence that we present in this paper we suggest that the RTI method that we implemented provides a robust basis for remediating early failure to learn to write. Its efficacy, we believe, lies in a) continuous progress monitoring, b) remedial intervention under ongoing classroom instruction and c) feasibility of implementation in regular first-grade classes.

\section{References}

Abbott, R. D., \& Berninger, V. W. (1993). Structural equation modeling of relationships among developmental skills and writing skills in primary- and intermediate-grade writers. Journal of Educational Psychology, 85(3), 478-508. https://doi.org/10.1037/0022-0663.85.3.478

Abbott, R. D., \& Berninger, V. W. (1993). Structural equation modeling of relationships among developmental skills and writing skills in primary- and intermediate-grade writers. Journal of Educational Psychology, 85(3), 478-508. https://doi.org/10.1037/0022-0663.85.3.478

Alves, R. A., Limpo, T., \& Fidalgo, R. (2016). The Impact of Promoting Transcription on Early Text 
Production : Effects on Bursts and Pauses, Levels of Written Language, and Writing Performance, 108(5), 665-679.

Barnes, A. C., \& Harlacher, J. E. (2008). Clearing the Confusion : Response-to-Intervention as a Set of Principles. Education and Treatment of Children, 31(3), 417-431.

https://doi.org/https://doi.org/10.1353/etc.0.0000

Berninger, V. W., Vaughan, K., Abbott, R. D., Begay, K., Coleman, K. B., Curtin, G., .. Graham, S. (2002). Teaching spelling and composition alone and together: Implications for the simple view of writing. Journal of Educational Psychology, 94(2), 291-304.

Brown-Chidsey, R., \& Steege, M. (2005). Response to Intervention. Principles and strategies for effective practice. (R. Brown-Chidsey \& M. Steege, Eds.). New York: Guildford Press.

Camacho, A., \& Alves, R. A. (2017). Fostering parental involvement in writing : development and testing of the program Cultivating Writing. Reading and Writing, 30(2), 253-277.

https://doi.org/10.1007/s11145-016-9672-6

Christensen, J. D. \& C. . (1999). Relationship between automaticity in handwriting and students' ability to generate written text. Journal of Educational Psychology, 91(1), 44-49. https://doi.org/10.1037//00220663.91.1.44

Coker, D. (2006). Impact of First-Grade Factors on the Growth and Outcomes of Urban Schoolchildren's Primary-Grade Writing. Journal of Educational Psychology, 98(3), 471-488. https://doi.org/10.1037/0022-0663.98.3.471

Cuetos, F., Sánchez, C., \& Ramos, J. L. (1996). Evaluación de los procesos de escritura en niños de educación primaria. Bordón, 48(4), 445-456.

Cutler, L., \& Graham, S. (2008). Primary Grade Writing Instruction: A National Survey. Journal of Educational Psychology, 100(4), 907-919. https://doi.org/10.1037/a0012656

Defior, S., Jiménez-Fernández, G., \& Serrano, F. (2009). Complexity and lexicality effects on the acquisition of Spanish spelling. Learning and Instruction, 19(1), 55-65. 
https://doi.org/10.1016/j.learninstruc.2008.01.005

Dockrell, J. E., Marshall, C. R., \& Wyse, D. (2015). Teachers' reported practices for teaching writing in England. Reading and Writing. https://doi.org/10.1007/s11145-015-9605-9

Dunsmuir, S., \& Blatchford, P. (2004). Predictors of writing competence in 4- to 7-year-old children. The British Journal of Educational Psychology, 74(3), 461-83. https://doi.org/10.1348/0007099041552323

Fidalgo, R., \& Torrance, M. (n.d.). Developing Writing Skills through Cognitive Self-Regulation Instruction. In Design Principles for Teaching Effective Writing (pp. 89-118). Brill. https://doi.org/10.1163/9789004270480_006

Gersten, R., \& Baker, S. (2001). Teaching Expressive Writing to Students with Learning Disabilities : A Meta-Analysis. The Elementary School Journal, 101(3), 251-272. https://doi.org/https://doi.org/10.1177/002221940303600204

Gillespie, A., \& Graham, S. (2014). A Meta-Analysis of Writing Interventions for Students With Learning Disabilities. Exceptional Children, 80(4), 454-473. https://doi.org/10.1177/0014402914527238

Glaser, C., \& Brunstein, J. C. (2007). Improving fourth-grade students' composition skills: Effects of strategy instruction and self-regulation procedures. Journal of Educational Psychology, 99(2), 297-310. https://doi.org/10.1037/0022-0663.99.2.297

Graham, S., Berninger, V. W., Abbott, R. D., Abbott, S. P., \& Whitaker, D. (1997, March). Role of mechanics in composing of elementary school students: A new methodological approach. Journal of Educational Psychology. https://doi.org/10.1037/0022-0663.89.1.170

Graham, S., \& Harris, K. (2015). Evidence-Based Writing Practices: a Meta-Analysis of existing metaanalysis. In R. Fidalgo, K. Harris, \& M. Braaksma (Eds.), Design principles for teaching effective writing: theoretical and empirical grounded principles. Leiden: Brill Editions.

Graham, S., Harris, K. R., \& Fink, B. (2000). Is handwriting causally related to learning to write? Treatment of handwriting problems in beginning writers. Journal of Educational Psychology, 92(4), 620633. https://doi.org/10.1037/0022-0663.92.4.620 
Graham, S., Harris, K. R., \& Fink, B. (2002). Contribution of spelling instruction to the spelling, writing, and reading of poor spellers. Journal of Educational Psychology, 94(4), 669-686.

https://doi.org/https://doi.org/10.1037//0022-0663.94.4.669

Graham, S., Harris, K. R., \& Larsen, L. (2001). Prevention and Intervention of Writing Difficulties for Students with Learning Disabilities. Learning Disabilities Research \& Practice, 16(2), 74-84. https://doi.org/https://doi.org/10.1111/0938-8982.00009

Graham, S., McKeown, D., Kiuhara, S., \& Harris, K. R. (2012). A meta-analysis of writing instruction for students in the elementary grades. Journal of Educational Psychology, 104(4), 879-896. https://doi.org/10.1037/a0029185

Graham, S., \& Santangelo, T. (2014). Does spelling instruction make students better spellers, readers, and writers? A meta-analytic review. Reading and Writing, 27(9), 1703-1743. https://doi.org/10.1007/s11145-014-9517-0

Harris, K., Graham, S., \& Mason, L. (2006). Improving the writing, knowledge, and motivation of young struggling writers: Effects of self-regulated strategy development with and without peer support. American Educational Research Journal, 43, 295-340.

Harris, K. R., Graham, S., \& Adkins, M. (2014). Practice-based professional development and SelfRegulated Strategy Development for Tier 2, at-risk writers in second grade. Contemporary Educational Psychology. https://doi.org/10.1016/j.cedpsych.2014.02.003

Hooper, S. R., Roberts, J. E., Nelson, L., Zeisel, S., \& Kasambira, D. (2010). Preschool predictors of narrative writing skills in elementary school children. School Psychology Quarterly, 25(1), 1-12. https://doi.org/10.1037/a0018329

Jones, D. (2004). Automaticity of the transcription process in the production of written text. University of Queensland, Queensland, Australia.

Karahmadi, M., Shakibayee, F., Amirian, H., Bagherian-Sararoudi, R., \& Maracy, M. R. (2013). Efficacy of parenting education compared to the standard method in improvement of reading and writing 
disabilities in children. Iranian Journal of Psychiatry and Behavioral Sciences, 8(1), 51-8.

Lane, K. L., Harris, K., Graham, S., Driscoll, S., Sandmel, K., Morphy, P., ... Schatschneider, C. (2011). Self-Regulated Strategy Development at Tier 2 for Second-Grade Students With Writing and Behavioral Difficulties: A Randomized Controlled Trial. Journal of Research on Educational Effectiveness, 4(4), 322-353. https://doi.org/10.1080/19345747.2011.558987

Lane, K. L., Harris, K. R., Graham, S., Weisenbach, J. L., Brindle, M., \& Morphy, P. (2008). The Effects of Self-Regulated Strategy Development on the Writing Performance of Second-Grade Students With Behavioral and Writing Difficulties. Journal of Special Education, 41(4), 234-253.

Lienemann, T. O., Graham, S., Leader-Janssen, B., \& Reid, R. (2006). Improving the Writing Performance of Struggling Writers in Second Grade. The Journal of Special Education, 40(2), 66-78. https://doi.org/https://doi.org/10.1177/00224669060400020301

Limpo, T., \& Alves, R. A. (2013). Modeling writing development: Contribution of transcription and selfregulation to Portuguese students' text generation quality. Journal of Educational Psychology, 105(2), 401413. https://doi.org/10.1037/a0031391

Limpo, T., \& Alves, R. A. (2017). Tailoring Multicomponent Writing Interventions: Effects of Coupling Self-Regulation and Transcription Training. Journal of Learning Disabilities, 2221941770817. https://doi.org/10.1177/0022219417708170

Martínez, J., \& García, E. (2004). Diccionario: frecuencias del castellano escrito en niños de 6 a 12 años. Salamanca: Universidad Pontificia de Salamanca.

O’Connor, R. E., Fulmer, D., Harty, K. R., \& Bell, K. M. (2005). Tiers of Reading Intervention in Kindergarten Through Third Grade. Journal of Learning Disabilities, 38(6), 532-538. https://doi.org/10.1177/00222194050380050701

Olive, T., Alves, R. A., \& Castro, S. L. (2009). Cognitive processes in writing during pause and execution periods. European Journal of Cognitive Psychology, 21(5), 758-785. https://doi.org/10.1080/09541440802079850 
Olive, T., \& Kellogg, R. T. (2002). Concurrent activation of high- and low-level production processes in written composition. Memory \& Cognition, 30(4), 594-600. https://doi.org/10.3758/BF03194960

Raven, J. C. (1981). Manual for Raven's progressive matrices and vocabulary scale. (J. C. Raven, Ed.). Texas: Psychological Corporation.

Reutzel, D. R., Fawson, P. C., \& Smith, J. A. (2005). Words to Go!: Evaluating a First-Grade Parent Involvement Program for "Making" Words at Home. Reading Research and Instruction, 45(2), 119-159. https://doi.org/10.1080/19388070609558445

Robledo-Ramón, P., \& García-Sánchez, J. N. (2012). Preventing children’s writing difficulties through specific intervention in the home. In W. Sittiprapaporn (Ed.), Learning Disabilities. Croatia: InTech Europe.

Saint-Laurent, L., \& Giasson, J. (2005). Effects of a family literacy program adapting parental intervention to first graders' evolution of reading and writing abilities. Journal of Early Childhood Literacy, 5(3), 253278. https://doi.org/10.1177/1468798405058688

Santangelo, T., \& Graham, S. (2016). A Comprehensive Meta-analysis of Handwriting Instruction. Educational Psychology Review (Vol. 28). Educational Psychology Review. https://doi.org/10.1007/s10648-015$9335-1$

Simmons, D. C., Coyne, M. D., Kwok, O., McDonagh, S., Ham, B. A., \& Kame’enui, E. J. (2008). Indexing response to intervention: a longitudinal study of reading risk from kindergarten through third grade. Journal of Learning Disabilities, 41(2), 158-173. https://doi.org/10.1177/0022219407313587

Torrance, M., Fidalgo, R., \& García, J.-N. (2007). The teachability and effectiveness of cognitive selfregulation in sixth-grade writers. Learning and Instruction, 17(3), 265-285.

https://doi.org/10.1016/j.learninstruc.2007.02.003

van den Bergh, H., Maeyer, S., van Weijen, D., \& Tillema, M. (2012). Generalizability of Text Quality Scores. In E. Van Steendam, M. Tillema, G. Rijlaarsdam, \& H. van den Bergh (Eds.), Measuring 
Writing: Recent Insights into Theory, Methodology and Practice (pp. 23-32). Leiden, NL: Brill.

https://doi.org/10.1163/9789004248489_003

Vanderheyden, A. M., Witt, J. C., \& Gilbertson, D. (2007). A multi-year evaluation of the effects of a

Response to Intervention ( RTI ) model on identification of children for special education 2 . Journal

of School Psychology, 45(2), 225-256. https://doi.org/10.1016/j.jsp.2006.11.004

Vaughn, S., \& Fuchs, L. S. (2003). Redefining Learning Disabilities as Inadequate Response to

Instruction : The Promise and Potential Problems. Learning Disabilities Research \& Practice, 18(3), 137-

146. https://doi.org/https://doi.org/10.1111/1540-5826.00070

Vaughn, S., Linan-thompson, S., \& Hickman, P. (2003). Response to Intervention as a means of

identifying studens with reading/learning diabilities. Exceptional Children, 69(4), 391-409.

Zumbrunn, S., \& Bruning, R. (2013). Improving the writing and knowledge of emergent writers : the

effects of self-regulated strategy development. Reading and Writing, 26(1), 91-110.

https://doi.org/10.1007/s11145-012-9384-5

\section{Appendix A}

\begin{tabular}{|c|c|}
\hline \multicolumn{2}{|l|}{ Handwriting scale } \\
\hline Score & criteria \\
\hline $\begin{array}{c}0 \\
\text { NO } \\
\text { HANDWRITING }\end{array}$ & $\begin{array}{l}\text { The following cases will score } 0 \text { : } \\
\text { - The child is unable to produce letters, so the sheet is either blank or with } \\
\text { pictures or ramdom strokes on it. } \\
\text { - The child is unable to produce any recognisable words. They just write ramdom } \\
\text { combinations of letters. }\end{array}$ \\
\hline $\begin{array}{l}1 \\
\text { REALLY POOR } \\
\text { HANDWRITING }\end{array}$ & $\begin{array}{l}\text { Most of the text is illegible either because letters are poorly written or words are formed } \\
\text { by ramdom combination of letters (or both). However, there are at least } 2 \text { legible words, } \\
\text { formed with simple letter combinations (e.g "mum", "dad", "and"...). } \\
\text { Very short texts with } 2 \text { or } 3 \text { words will score } 1 \text { if at least } 1 \text { word is legible. }\end{array}$ \\
\hline
\end{tabular}




\begin{tabular}{|c|c|}
\hline $\begin{array}{c}2 \\
\text { POOR } \\
\text { HANDWRITING }\end{array}$ & $\begin{array}{l}\text { Between } 50 \% \text { and } 75 \% \text { of text is legible, although there can be some illegible } \\
\text { words/letters. There should be at least one legible complete sentence, although not } \\
\text { necessarily complex. Understanding the text requires an additional effort by the reader } \\
\text { since some or all of these mistakes are frequently made: } \\
\text { - Shaky and irregular strokes. } \\
\text { - } \quad \text { Great variety in letter size. } \\
\text { - Oscillations of letters and words. } \\
\text { - Big gaps between letters of the same word. } \\
\text { - Overlapped letters. }\end{array}$ \\
\hline $\begin{array}{c}3 \\
\text { ACCEPTABLE/ } \\
\text { AVERAGE } \\
\text { HANDWRITING }\end{array}$ & $\begin{array}{l}\text { The whole text is legible although there might be } 1 \text { or } 2 \text { illegible words. Understanding } \\
\text { the text does not require any additional effort by the reader. Some of the previous } \\
\text { mistakes are made but they hardly ever occur. }\end{array}$ \\
\hline $\begin{array}{c}4 \\
\text { NICE } \\
\text { HANDWRITING }\end{array}$ & $\begin{array}{l}\text { The text is perfectly legible and it gives a feeling of neatness, order and cleanliness. } \\
\text { Previous mistakes do not occur, although there might be } 1 \text { or } 2 \text { slightly irregular letters. }\end{array}$ \\
\hline
\end{tabular}




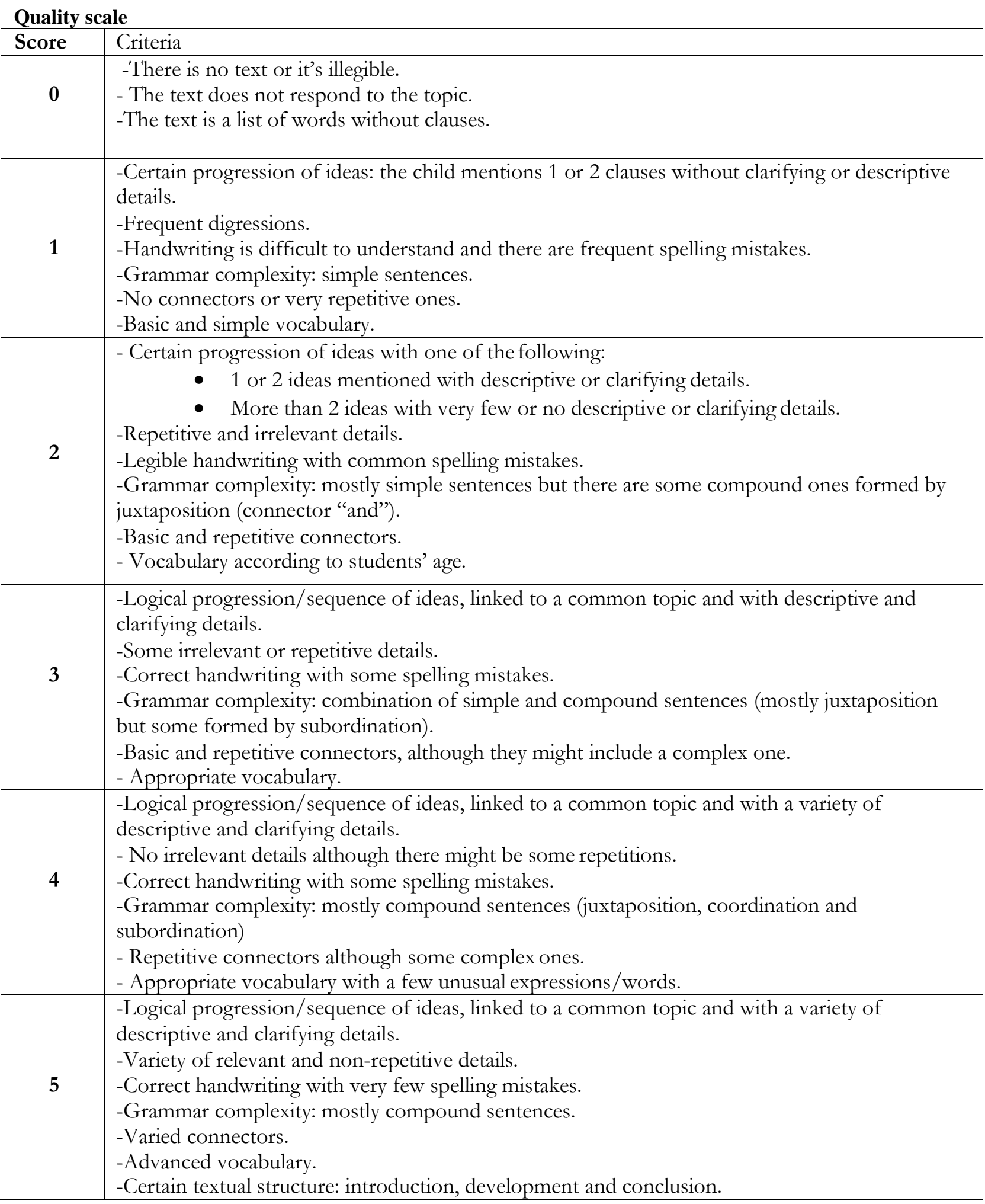


Appendix B: Test statistics associated with $\mathrm{p}$ values reported in Table 1: Standardized regression coefficient, $t$, residual degrees of freedom.

\begin{tabular}{|c|c|c|c|c|c|c|c|c|}
\hline & & & & & \multicolumn{4}{|c|}{ Word count } \\
\hline & \multicolumn{2}{|c|}{ Overall Quality } & \multicolumn{2}{|c|}{ Handwriting } & \multicolumn{2}{|c|}{ Total } & \multicolumn{2}{|c|}{ Correctly Spelled } \\
\hline & Main effect & Learning rate & Main effect & Learning rate & Main effect & Learning rate & Main effect & Learning rate \\
\hline \multicolumn{9}{|c|}{ No Intervention } \\
\hline $\mathrm{S} 1$ & $0.65,4.01,21$ & $-0.2,-0.96,21$ & $0.49,3.5,21$ & $-0.49,-2.75,21$ & $0.27,1.56,21$ & $0.07,0.33,21$ & $0.46,2.89,21$ & $0.04,0.18,21$ \\
\hline $\mathrm{S} 2$ & $0.25,1.24,20$ & $0.04,0.18,20$ & $0.56,4.92,20$ & $-0.49,-3.46,20$ & $0.43,2.74,20$ & $-0.08,-0.42,20$ & $0.53,4.03,20$ & $-0.15,-0.93,20$ \\
\hline $\mathrm{S} 3$ & $0.25,1.22,20$ & $-0.13,-0.52,20$ &,,-- 20 &,,-- 20 & $0.37,2.27,20$ & $0.56,2.75,20$ & $0.36,2.15,20$ & $0.48,2.25,20$ \\
\hline $\mathrm{S} 4$ & $0.47,2.64,19$ & $-0.01,-0.06,19$ & $0.4,2.4,19$ & $-0.61,-2.76,19$ & $0.42,3.03,19$ & $-0.04,-0.19,19$ & $0.39,2.67,19$ & $-0.1,-0.53,19$ \\
\hline $\mathrm{S} 5$ & $0.2,1.3,36$ & $-0.25,-1.28,36$ & $-0.25,-1.8,36$ & $0.46,2.53,36$ & $-0.14,-1.17,36$ & $-0.43,-2.73,36$ & $-0.11,-0.92,36$ & $-0.43,-2.79,36$ \\
\hline $\mathrm{S} 6$ & $0.15,0.85,31$ & $-0.21,-1.06,31$ & $0.14,0.93,31$ & $-0.33,-1.91,31$ & $0.11,0.64,31$ & $-0.27,-1.28,31$ & $0.16,0.9,31$ & $-0.35,-1.78,31$ \\
\hline $\mathrm{S} 7$ & $0.35,2.44,37$ & $-0.37,-2.06,37$ & $0.42,4,37$ & $-0.55,-4.17,37$ & $0.13,0.79,37$ & $-0.09,-0.42,37$ & $0.19,1.22,37$ & $-0.17,-0.83,37$ \\
\hline \multicolumn{9}{|c|}{ Transcription-Only } \\
\hline $\mathrm{S} 8$ & $0.61,5.36,36$ & $0.26,1.81,36$ & $0.88,13.72,36$ & $0.2,2.39,36$ & $0.05,0.3,36$ & $0.41,2.04,36$ & $0.29,1.98,36$ & $0.46,2.49,36$ \\
\hline S9 & $0.52,4.58,36$ & $0.34,2.33,36$ & $0.64,5.68,36$ & $0.25,1.72,36$ & $0.22,1.52,36$ & $0.51,2.75,36$ & $0.47,3.73,36$ & $0.39,2.42,36$ \\
\hline $\mathrm{S} 10$ &,,-- 29 &,,-- 29 & $0.97,14.9,29$ & $0.14,1.78,29$ & $0.8,6.99,29$ & $-0.03,-0.23,29$ & $0.69,5.62,29$ & $-0.22,-1.48,29$ \\
\hline $\mathrm{S} 11$ & $0.9,13.41,33$ & $0.19,2.39,33$ & $0.84,8.9,33$ & $0.01,0.11,33$ & $0.62,4.59,33$ & $-0.02,-0.16,33$ & $0.63,4.7,33$ & $-0.11,-0.7,33$ \\
\hline $\mathrm{S} 13$ & $0.79,7.04,26$ & $-0.13,-0.99,26$ & $0.85,8.48,26$ & $-0.03,-0.24,26$ & $0.67,4.63,26$ & $0.08,0.46,26$ & $0.71,5.04,26$ & $0.09,0.53,26$ \\
\hline \multicolumn{9}{|c|}{ Transcription-and-Planning } \\
\hline $\mathrm{S} 14$ & $0.71,5.19,20$ & $-0.17,-0.97,20$ & $0.87,10.81,20$ & $-0.01,-0.14,20$ & $0.69,4.99,20$ & $-0.53,-3.02,20$ & $0.73,6.35,20$ & $-0.56,-3.83,20$ \\
\hline S15 & $0.37,2.63,34$ & $0.46,2.48,34$ & $0.46,3.64,34$ & $0.54,3.21,34$ & $-0.15,-1.11,34$ & $0.73,4.19,34$ & $0.33,2.22,34$ & $0.42,2.11,34$ \\
\hline S16 & $0.64,6.5,32$ & $-0.17,-1.23,32$ & $0.77,10.53,32$ & $-0.33,-3.24,32$ & $0.7,7.14,32$ & $0.06,0.43,32$ & $0.76,8.65,32$ & $0,-0.02,32$ \\
\hline
\end{tabular}




\begin{tabular}{lllcllccc} 
S17 & $0.87,12.79,33$ & $-0.09,-1.16,33$ & $0.81,9.5,33$ & $-0.07,-0.68,33$ & $0.77,7.62,33$ & $0.24,2.07,33$ & $0.77,7.77,33$ & $0.27,2.36,33$ \\
S18 & $0.3,1.88,32$ & $0.29,1.56,32$ & $0.93,16.9,33$ & $-0.18,-2.77,33$ & $0.55,3.95,33$ & $0.28,1.74,33$ & $0.67,5.32,33$ & $0.14,0.93,33$ \\
S19 & $0.8,12.94,28$ & $0.08,1.11,28$ & $0.85,15.55,28$ & $0.06,0.97,28$ & $0.66,5.33,28$ & $0.05,0.35,28$ \\
S20 & $0.54,5.09,29$ & $-0.1,-0.76,29$ & $0.67,7.21,29$ & $-0.12,-1.09,29$ & $0.44,3.14,29$ & $0.29,1.73,29$ & $0.59,5.59,28$ \\
\hline
\end{tabular}

Note: Values from phase (main effect) and phase x time (learning rate) effects from linear models. Dashes indicate values that could not be calculated. 


\section{Appendix C: Observed scores on phase-end tests.}

Cohort (means with standard deviation in parenthesis) represents all students in classes from which the intervention students were sampled, excluding the intervention students.

\begin{tabular}{|c|c|c|c|c|c|c|c|c|c|c|c|c|}
\hline & \multicolumn{3}{|c|}{ Narrative Quality } & \multicolumn{3}{|c|}{ Handwriting Speed } & \multicolumn{3}{|c|}{ Spelling } & \multicolumn{3}{|c|}{ Non-verbal } \\
\hline & Pre & Tier 1 Post & Tier 2 Post & Pre & Tier 1 Post & Tier 2 Post & Pre & Tier 1 Post & Tier 2 Post & Pre & Tier 1 Post & Tier 2 Post \\
\hline Cohort & $3(2.3)$ & $5.5(2.3)$ & $7.1(2.0)$ & $3.7(2.1)$ & $8.1(2.6)$ & $11.5(3.2)$ & $26.9(10.6)$ & $37.2(4.4)$ & $39.7(3.9)$ & $14.9(2.7)$ & $16.5(2.3)$ & $16.9(2.1)$ \\
\hline \multicolumn{13}{|c|}{ No Intervention } \\
\hline S1 & 0 & 7 & 9 & 4 & 11 & 17 & 9 & 30 & 39 & 1 & 13 & 11 \\
\hline S2 & 1 & 6 & 7 & 2 & 6 & 7 & 29 & 39 & 39 & 14 & 18 & 18 \\
\hline S3 & 5 & 6 & 7 & 2 & 7 & 9 & 31 & 36 & 41 & 14 & 19 & 18 \\
\hline S4 & 1 & 6 & 10 & 2 & 8 & 13 & 20 & 39 & 38 & 17 & 17 & 18 \\
\hline S5 & 5 & 3 & 7 & 2 & 6 & 11 & 35 & 41 & 41 & 16 & 14 & 15 \\
\hline S6 & 0 & 0 & 6 & 0 & 5 & 8 & 5 & 36 & 37 & 16 & 14 & 18 \\
\hline S7 & 0 & 7 & 5 & 3 & 12 & 14 & 25 & 36 & 34 & 10 & 12 & 14 \\
\hline \multicolumn{13}{|c|}{ Transcription only } \\
\hline S8 & 0 & 0 & 6 & 1 & 8 & 18 & 8 & 9 & 24 & 14 & 11 & 14 \\
\hline S9 & 0 & 0 & 7 & 0 & 4 & 9 & 11 & 21 & 30 & 9 & 13 & 13 \\
\hline $\mathrm{S} 10$ & 0 & 0 & 2 & 1 & 0 & 0 & 1 & 0 & 0 & 10 & 9 & 12 \\
\hline S13 & 0 & 0 & 8 & 0 & 5 & 6 & 0 & 22 & 39 & 14 & 15 & 16 \\
\hline \multicolumn{13}{|c|}{ Transcription and Planning } \\
\hline S14 & 0 & 0 & 1 & 0 & 6 & 12 & 5 & 23 & 29 & 11 & 15 & 16 \\
\hline $\mathrm{S} 15$ & 0 & 0 & 0 & 1 & 0 & 1 & 2 & 0 & 0 & 14 & 16 & 13 \\
\hline S16 & 0 & 2 & 8 & 2 & 6 & 9 & 9 & 34 & 36 & 11 & 16 & 20 \\
\hline S17 & 0 & 3 & 7 & 0 & 4 & 14 & 0 & 24 & 36 & 18 & 19 & 20 \\
\hline S18 & 0 & 0 & 2 & 0 & 0 & 0 & 0 & 0 & 1 & 11 & 15 & 15 \\
\hline S19 & 0 & 0 & 6 & 0 & 7 & 10 & 0 & 33 & 34 & 12 & 11 & 11 \\
\hline S20 & 0 & 0 & 6 & 0 & 4 & 7 & 0 & 24 & 36 & 10 & 10 & 14 \\
\hline
\end{tabular}




\section{Tables and Figures}

\section{Figure Captions}

Figure 1. Text quality ratings from probe writing tasks in Phases 1 and 2.

Figure 2. Handwriting quality ratings for probe writing tasks in Phases 1 and 2.

Figure 3. Word count overall (points and solid regression lines) and for correctly spelled words (dashed regression lines) in Phases 1 and 2.

Figure 4. Performance at start of year and, Phase 1 posttest and Phase 2 posttest, relative to peers. 
Table 1. Significance tests for overall effect and difference in learning rate in Phase 1 and Phase 2. Negative effects shown in parenthesis.

\begin{tabular}{|c|c|c|c|c|c|c|c|c|}
\hline & \multirow{2}{*}{\multicolumn{2}{|c|}{ Overall Quality }} & \multirow{2}{*}{\multicolumn{2}{|c|}{ Handwriting }} & \multicolumn{4}{|c|}{ Word count } \\
\hline & & & & & \multicolumn{2}{|c|}{ Total } & \multicolumn{2}{|c|}{ Correctly Spelled } \\
\hline & $\begin{array}{l}\text { Main } \\
\text { effect }\end{array}$ & $\begin{array}{c}\text { Learning } \\
\text { rate }\end{array}$ & $\begin{array}{l}\text { Main } \\
\text { effect }\end{array}$ & $\begin{array}{l}\text { Learning } \\
\text { rate }\end{array}$ & $\begin{array}{l}\text { Main } \\
\text { effect }\end{array}$ & $\begin{array}{c}\text { Learning } \\
\text { rate }\end{array}$ & $\begin{array}{l}\text { Main } \\
\text { effect }\end{array}$ & $\begin{array}{c}\text { Learning } \\
\text { rate }\end{array}$ \\
\hline \multicolumn{9}{|c|}{ No Intervention } \\
\hline S1 & $* * *$ & & $* *$ & $(*)$ & & & $* *$ & \\
\hline S2 & & & $* * *$ & $(* *)$ & $*$ & & $* * *$ & \\
\hline S3 & & & & & * & * & * & * \\
\hline S4 & * & & * & $(*)$ & $* *$ & & * & \\
\hline S5 & & & $(\circ)$ & * & & $\left({ }^{*}\right)$ & & $(* *)$ \\
\hline S6 & & & & (०) & & & & (०) \\
\hline S7 & $(*)$ & $(*)$ & $* * *$ & $(* * *)$ & & & & \\
\hline \multicolumn{9}{|c|}{ Transcription-Only } \\
\hline S8 & $* * *$ & 。 & $* * *$ & $*$ & & $* *$ & & * \\
\hline S9 & $* * *$ & * & $* * *$ & 。 & & $* *$ & $* * *$ & * \\
\hline $\mathrm{S} 10$ & & & $* * *$ & 。 & $* * *$ & & $* * *$ & $(* *)$ \\
\hline S11 & $* * *$ & * & $* * *$ & & $* * *$ & & $* * *$ & \\
\hline S13 & $* * *$ & & $* * *$ & & $* *$ & & $* *$ & \\
\hline \multicolumn{9}{|c|}{ Transcription-and-Planning } \\
\hline S14 & $* * *$ & & $* * *$ & & * & $(*)$ & $* *$ & $(*)$ \\
\hline S15 & * & * & $* * *$ & $* *$ & & $* * *$ & * & * \\
\hline S16 & $* * *$ & & $* * *$ & $(* *)$ & $* * *$ & & $* * *$ & \\
\hline S17 & $* * *$ & & $* * *$ & & $* * *$ & $*$ & $* * *$ & $*$ \\
\hline S18 & 。 & & $* * *$ & $(* *)$ & * & 。 & $* * *$ & \\
\hline S19 & $* * *$ & & $* * *$ & & $* * *$ & & $* * *$ & \\
\hline S20 & $* * *$ & & $* * *$ & & $* *$ & 。 & $* * *$ & \\
\hline
\end{tabular}

Note: $\mathrm{p}$ values from phase (main effect) and phase $\mathrm{x}$ time (learning rate) effects from linear models. ${ }^{\circ} \mathrm{p}<.1, * \mathrm{p}<.05, * * \mathrm{p}<.01, * * * \mathrm{p}<.001$. 
